\section{African wild ass}

Bill Clark

The African wild ass is endangered. Its habitat is a drought-stricken war zone; its flesh is eaten and is believed to cure hepatitis; it is eagerly sought by dealers and collectors. The author, Chief Curator at Israel's Hai-Bar reserve, examines the problems hindering the conservation of this animal and explains why it is urgently necessary to list it on Appendix I of the Convention on International Trade in Endangered Species of Wild Fauna and Flora at its meeting in April 1983.

The African wild ass Equus africanus is probably the most endangered wild equine on earth: its wild and captive breeding populations are minimal; its wild populations are subject to persistent poaching; its native habitat is a war zone, also affected by drought and over-grazing by domestic livestock. Conservation efforts are microscopic: none of the habitat countries is Party to CITES and the species is not even mentioned on the CITES appendices.

Add to this the extraordinary interest which some animal dealers have in acquiring specimens, plus the bizarre belief in the habitat countries that the flesh can cure hepatitis, and you have a fairly certain recipe for extinction.

Although the scenario is bleak, there are a few prospects for hope. First, there is opportunity to afford international protection to the African wild ass at the next Conference of the Parties to CITES in April 1983 when delegations from both the United States and Israel will present proposals to include the species on Appendix I of the Conven- tion. Equus africanus is not listed on the CITES appendices, according to the Secretariat, simply because nobody ever proposed it - even though it is classified as endangered in the IUCN's Red Data Book where the first proposed conservation measure listed is inclusion in Appendix I of the Convention on International Trade in Wild Species (sic) of Fauna and Flora. This proposal was published in 1976.

While conservationists have been slow to propose protective measures for this rare equine, the international animal exploiters have also been stalled for the time being. The African wild ass lives in an extremely remote and hostile habitat, in countries where the political situation is, at best, unstable.

Two subspecies now exist, africanus, the Nubian wild ass, numbering perhaps 1500 animals in southern Sudan, near the Red Sea coast (Watson et al., 1977), and somalicus, the Somali wild ass, of about 2000 animals living in the Ethiopian Danakil Desert and the Las 'Anod region of Somalia (Simonetta, 1982; Stephenson, 1976). Formerly, the African wild ass inhabited most of North Africa, from the Atlas Mountains in the west to Somalia in the east, and north into the Middle East. Two other subspecies, atlanticus and palestinae are now considered extinct.

Klingel $(1970,1971)$ made exhaustive studies of the somalicus subspecies and estimated a total population of 3000 animals. Since then estimates of the somalicus population have shown a steady decline.

The main population centre is in Ethiopia, along the northernmost stretches of the Awash River. The habitat is physically hostile-indeed, it is a testament to the species' endurance that it lives there. The region is also a traditional no-man'sland between the constantly warring Issa and Affar tribes. Consider also the recent Eritrean revolution in the region and the arrival of Soviet and Cuban 'technicians'. The Sahel drought left its mark and livestock grazing is reportedly on the increase.

Livestock grazing affects Equus africanus in two ways. First, domestic animals eat much of the vegetation which otherwise would have served as food for the wild ass-and indeed, certain livestock, particularly goats, graze so closely as to kill

African wild ass 


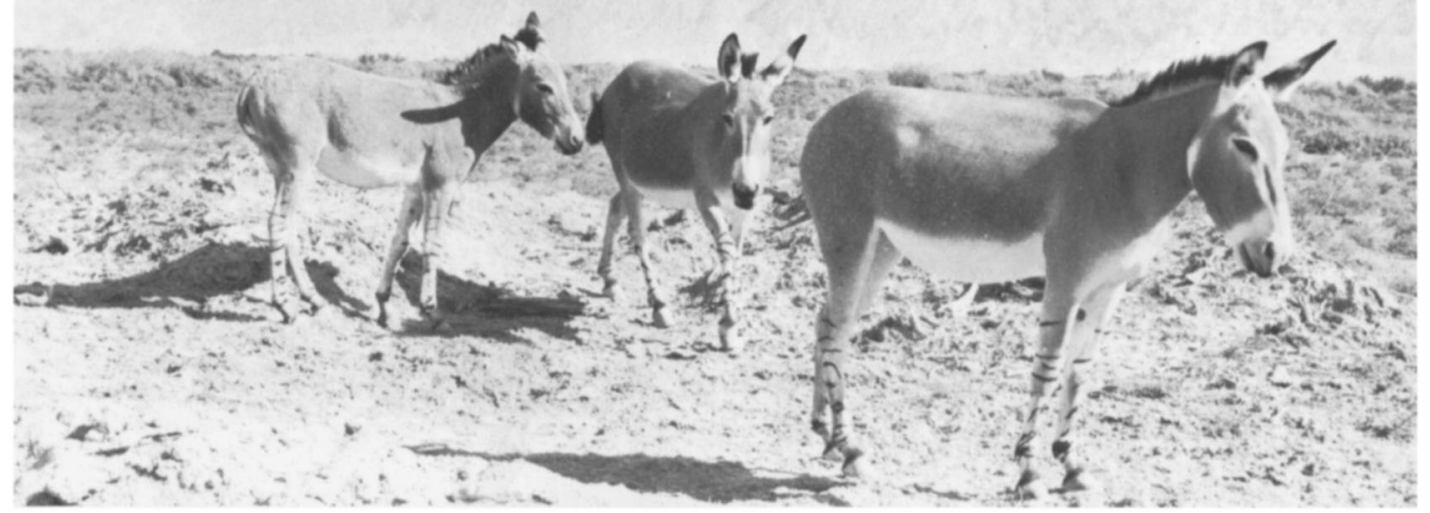

Three female Equus africanus somalicus on the open range of Hai-Bar Arava in Israel's Negev Desert. In the background are the Mountains of Edom.

the plants and thereby eliminate the grazing for every animal for some years. Second, the livestock, with their shepherds, concentrate at available watering areas, and the human presence in particular makes the area unsuitable for the prudently wary wild ass.

The unstable political situation and the fact that the asses are difficult to catch, have tended to discourage animal dealers from capture attempts in recent years. Indeed, there have been only two known legal expeditions which successfully captured the African wild ass during the past several decades, the 1972 Shultz expedition for Catskill Game Farm, and the 1970 Hunt expedition for International Animal Exchange. Hunt's (1970) graphic account of the chase is enough to discourage all but the most persistent dealers. It took nearly four months, employed 25 men, six trucks and landrovers, two aircraft 'plus great supplies of food and miscellaneous items' to catch five African wild asses. The chase led them over extremely rugged terrain, where the animals galloped upwards of $70 \mathrm{~km}$ per $\mathrm{hr}$-twice the speed of chased zebras. Veteran wildlife catcher Don Hunt described it as the most difficult capture operation I have ever experienced'.

These de facto protections - the insecurity of the region and the difficulty of capture-could

African wild ass evaporate overnight. As the conflicts in the region become less intense, and revolutionary governments consolidate control, the new wildlife officials and bureaucrats may be surprised to learn they can sell capture permits at, for example, $\$ 50,000$ for a herd of ten animals. Most wildlife dealers would willingly pay this much for a permit. Difficulty in capturing the African wild ass has been greatly reduced in the past couple of years with the refinement of etorphine hydrochloride (M99, Immobilon). Until the development of this drug, the wild ass simply could not be captured by use of a syringe dart. Xylazine could bring down Cape buffalo and elephant. Ketamine hydrochloride could slip gorillas and lions into blissful slumber. The wild ass responded to these drugs as if they were soda pop but etorphine hydrochloride, according to Fowler (1978), has up to 10,000 times the analgesic potency of morphine hydrochloride. With just a few milligrams in a dart, a man can catch the African wild ass standing 100 yards away. The animal is virtually paralysed and can be put into a transport box with little difficulty. The capture expedition can be reduced to two men and an old jeep.

Because of the potential for bribes, and the great facility in capture, the African wild ass is today very vulnerable to exploitation and international 


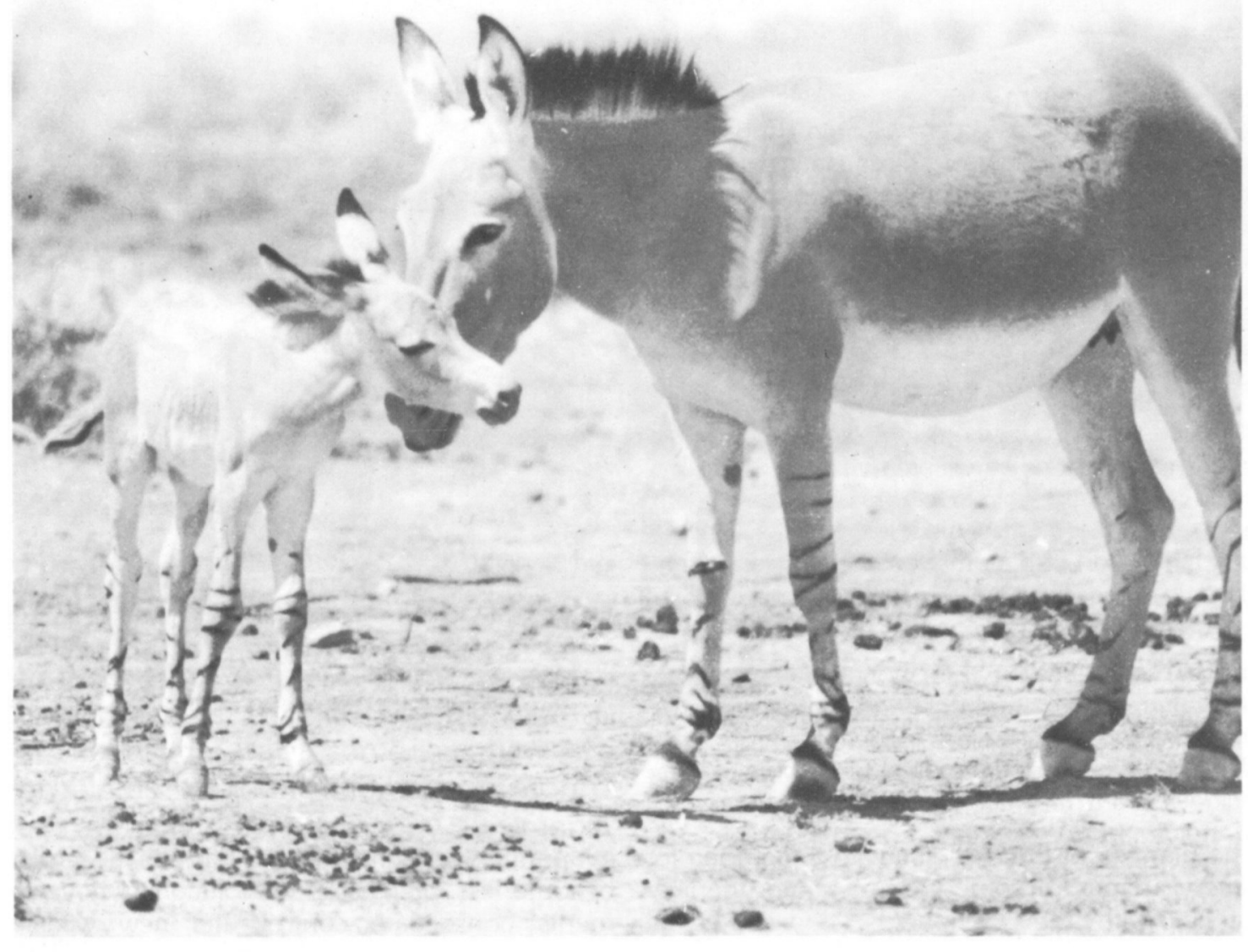

A new-born foal with his mother at Hai-Bar Arava.

trade. It seems imperative that CITES add the species to Appendix I at next April's Conference of the Parties thus preventing international trade before it starts.

The domestic situation however, will not be easy to deal with. Various authorities report poaching of this animal, and indeed 'poaching' seems to be merely a technical expression. The laws protecting the species in each habitat country are, apparently, usually ignored. An example of this was given by Professor Klingel (1970), chairman of the Species Survival Commission's African Equid Group, who reports that his African helpers offered to shoot specimens so he could inspect them more closely. Visiting conservationists also report that, in addition to the species's association with cures for hepatitis, locals also like to eat its flesh.

The few African wild asses in captivity are thriving. The Hunt expedition animals went to Basel Zoo, which is engaged in a promising breeding programme. The animals have an adequate paddock, a good diet, and superb veterinary care. The twelve animals captured by Shultz were destined for the Catskill Game Farm in the United States. Veterinary import restrictions prohibited the shipment and the animals were offered to and accepted by Israel's Hai-Bar programme. They were flown to Hai-Bar Arava, a $35 \mathrm{sq} \mathrm{km}$ wildlife reserve in the Negev Desert's Arava Valley where approximately $12 \mathrm{sq} \mathrm{km}$ are fenced in for the wildlife programme.

The wild asses were released into the fenced range and generally left alone. Occasionally individual animals were removed, to administer veterinary treatments or to terminate particularly vicious dominance struggles. The animals had room to establish normal social structures. There was adequate vegetation and water provided. The fence excluded predators. Generally, HaiBar animals enjoy a near-natural life with as little interference as possible from the staff.

Oryx Vol 17 No 1 
As chief curator of the reserve for nearly two years, I became acutely aware of the demand for African wild asses. I had more offers to purchase these animals - from animal dealers, zoological gardens and even private collectors-than all other Hai-Bar animals put together. This becomes particularly surprising when one realises all those other species included the white oryx Oryx leucoryx, the emblem of ffPS, the dorcas gazelle Gazella dorcas saudiya, Arabian gazelle Gazella g. arabica, addax Addax nasomaculatus, onager Equus hemionus onager, and several other species of rare and beautiful desert fauna.

The African wild ass formerly lived in Israel and the ultimate goal of Hai-Bar is to release it into natural areas of its native habitat once its population is large enough and it has adjusted well enough to the Negev ecosystems. Hai-Bar, with a current population of 20 African wild asses, protects more animals of this species than all other facilities on earth combined.

There may be some equines with smaller numbers than the African wild ass-such as Przewalski's wild horse Equus przewalskii and the Cape mountain zebra Equus zebra zebra-but these enjoy substantial conservation investments which have stopped their declines toward extinction and started increases in numbers. The African wild ass, on the other hand, depends on protective measures which are minute by comparison. The question of its survival must still be considered to be in the balance. Unless proper conservation steps are taken very soon, Equus africanus may be the next equine to follow Equus quagga into the oblivion of extinction. It is a sobering thought for the current centennial commemoration: the quagga disappeared from this earth when the last specimen died in the Amsterdam Zoo on 12 August 1882.

\section{Acknowledgments}

I would like to thank Friends of Animals, $11 \mathrm{~W}$. 60th St., NYC, which supported the researching of this article. Friends of Animals also sponsored a larger, detailed study I made of Equus africanus in order to satisfy the format established by CITES to propose the listing of species in Appendix I. This research has been presented to the scientific authorities of both the United States and Israel. Each of these authorities, in turn, is sponsoring individual proposals to list Equus africanus on Appendix I at the April 1983 Conference of the Parties. In particular, I would like to express my appreciation to both Alice Herrington and Harrison Maas of FoA for their close attention and support of this project.

\section{References}

Fowler, M.E. 1978. Restraint and Handling of Wild and Domestic Animals. Iowa State University Press, Ames, lowa.

Hunt, D. 1970. Locating and capturing the Somali wild ass, mimeo.

Klingel, H. 1970. Status Survey of the Somali Wild Ass in the Danakil Region Ethiopia. World Wildlife Fund field survey, mimeo.

Klingel, H. 1971. Somali Wild Ass: Status Survey in the Danakil Region. World Wildlife Fund field survey, mimeo.

Simonetta, A. 1982. Letter to IUCN re: Equus africanus.

Stephenson 1976. Untitled field survey of African wild ass distribution and population (part of a proposal to create Wild Ass National Park and Wildlife Reserve (Gweane)).

Watson, R.M. et al. 1977. Sudan Livestock Census and Resource Inventory. Veterinary Research Administration, Ministry of Agriculture, Food and Natural Resources, Khartoum.

Bill Clark, 3 Rehov Diskin, Jerusalem 92473, Israel. 